\title{
Debonding-Related Strain Limits for Externally Bonded FRP Sheets in Flexurally Strengthened Reinforced Concrete Beams
}

\author{
Guibing $\mathrm{Li}^{1, *}$, Aihui Zhang ${ }^{2}$ and Yugang $\mathrm{Guo}^{3}$ \\ ${ }^{I}$ College of Management Science and Engineering, Shandong Institute of Business \& Technology, Yantai 264005, China \\ ${ }^{2}$ College of Civil Engineering \& Architecture, Zhejiang University, Hangzhou 310058, China \\ ${ }^{3}$ International Business College, Shandong Institute of Business and Technology, Yantai, 264005, China
}

\begin{abstract}
Debonding problems of externally bonded fiber reinforced polymer (FRP) sheets in flexurally FRP-strengthened reinforced concrete (RC) beams have been a concern and a research challenge since their application of this strengthening technique. Intermediate crack induced debonding is the most common failure mode which is that the debonding initiates at the critical flexural-shear or flexural cracks and propagates towards the direction of moment decrease. To mitigate debonding failure, most Codes and proposed models take the method by limiting the allowable tensile strain in FRP laminates. This paper presents experimental tests of concrete beams flexurally strengthened with externally bonded CFRP sheets to investigate debonding initiation and tensile strain of FRP laminates. The allowable tensile strain of FRP sheets in flexurally FRP-strengthened RC beams proposed by prevalent Code provisions and models was assessed based on the data obtained from experimental programs. It has beenshown that the allowable tensile strains provided by these provisions and models have a great difference with that of experimental results and exhibit a high level of dispersion. Furthermore, the FRP laminates of most tested RC beams were debonded before reaching the proposed allowable tensile strain. The Code provisions and models are inadequate to effectively prevent intermediate crack induced debonding failure in flexurally FRP-strengthened RC members. This is known to be a critical issue in engineering design and application of RC beams flexurally strengthened by FRP sheets.
\end{abstract}

Keywords: RC Beam, FRP sheet, strengthening, debonding failure, allowable tensile strain.

\section{INTRODUCTION}

Debonding of externally bonded fiber reinforced polymer (FRP) sheets used for the rehabilitation and retrofitting of reinforced concrete flexural members has been commonly observed. The most commonly reported debonding mode in experimental literatures is the debonding initiates at critical flexural/shear and flexural cracks near the region of maximum moment. This failure mode of debonding is properly termed as intermediate crack-induced debonding. The prevalent Code provisions [1-6] and proposed models [7-10] for the design of externally bonded FRP systems often take the method by limiting the tensile strain or stress in the FRP laminates to mitigate debonding. Based on the tests results of flexurally FRP-strengthened RC beams failed cause of intermediate crack-induced debonding failure, this paper carried out a comprehensive comparison of the Code provisions and models and evaluated their validity and accuracy.

\section{EXPERIMENTAL PROGRAM}

8 simply supported beams, including A2 and B2 series, and 9 cantilever beams, including B1e, B2e and B2i series,

*Address correspondence to the author at the College of Management Science and Engineering, Shandong Institute of Business \& Technology, Yantai 264005, China; Tel: +86-535-6903575;

E-mails: liguibing@zju.edu.cn, leegb@sina.com were tested to investigate debonding process and tensile strain of FRP laminates in flexurally FRP-strengthened RC beams. The test specimens, series A2 and B2, used in the experimental program were prepared with varying properties: amount of tensile reinforcement and carbon fiber reinforced polymer (CFRP) sheets, preload level; for series B1e, B2e and B2i, the test variables are amount of CFRP sheets, preload level and anchorage method, respectively, see Table $\mathbf{1 .}$ Properties of materials used in these specimens are listed in Table 2. The mechanical properties of epoxy adhesive and CFRP sheets were provided by the manufacturer. The test set-ups and geometries of the tested beams are shown in Fig. (1) and Fig. (2).

\section{TEST RESULTS}

All the CFRP-strengthened RC beams failed by intermediate crack-induced debonding of CFRP laminates. The typical crack patterns of the strengthened beams are shown in Fig. (3). It can be observed during the test procedure that the width of the critical shear-flexural crack (CSFC) increased rapidly after the tension rebar yielding. Subsequently, a tributary crack formed adjacent to the CSFC, forming a triangular concrete block bounded by the CSFC, the tributary crack and the soffit of the beam; and then with the widening of the CSFC at beam soffit level was associated with the formation of a relative vertical displacement, as 
Table 1. Specimens and Test Variables

\begin{tabular}{|c|c|c|c|c|c|}
\hline \multirow{2}{*}{ Series } & Beam & Rebar & CFRP (Plies) & Preload & Anchor Program \\
\hline & A20* & & 2 & 0 & - \\
\hline \multirow[t]{3}{*}{$\mathrm{A} 2$} & A23 & & 2 & $0.3 P_{\mathrm{y}}$ & - \\
\hline & A26 & & 2 & $0.6 P_{\mathrm{y}}$ & - \\
\hline & A28 & & 2 & $0.8 P_{\mathrm{y}}$ & - \\
\hline \multirow[t]{4}{*}{$\mathrm{B} 2$} & $\mathrm{~B} 20$ & & 2 & 0 & - \\
\hline & B26 & & 2 & $0.3 P_{\mathrm{y}}$ & - \\
\hline & B28 & & 2 & $0.6 P_{\mathrm{y}}$ & - \\
\hline & $\mathrm{B} 23$ & & 2 & $0.8 P_{\mathrm{y}}$ & - \\
\hline \multirow{3}{*}{ B1e } & B10e & & 1 & 0 & external \\
\hline & B13e & & 1 & $0.3 P_{\mathrm{y}}$ & external \\
\hline & B16e & & 1 & $0.6 P_{\mathrm{y}}$ & external \\
\hline \multirow{3}{*}{ B2e } & B20e & & 2 & 0 & external \\
\hline & B23e & & 2 & $0.3 P_{\mathrm{y}}$ & external \\
\hline & B26e & & 2 & $0.6 P_{\mathrm{y}}$ & external \\
\hline \multirow{3}{*}{$\mathrm{B} 2 \mathrm{i}$} & B20i & & 2 & 0 & internal \\
\hline & B23i & & 2 & $0.3 P_{\mathrm{y}}$ & internal \\
\hline & B26i & & 2 & $0.6 P_{\mathrm{y}}$ & internal \\
\hline
\end{tabular}

*the first number denotes plies of CFRP laminates; the second number denotes the preload level corresponding to $0,0.3 P_{\mathrm{y}}, 0.6 P_{\mathrm{y}}$ and $0.8 P_{\mathrm{y}}$; and e and i denote external anchorage and internal anchorage, respectively.

Table 2. Properties of Materials

\begin{tabular}{|c|c|c|c|c|}
\hline \multirow{2}{*}{ Beams } & \multicolumn{3}{|c|}{ Strength(MPa) } & \multicolumn{2}{c|}{ Modulus (GPa) } \\
\cline { 2 - 5 } & $\boldsymbol{f}_{\text {cu }}$ & $\boldsymbol{f}_{\text {frp }}$ & $\boldsymbol{f}_{\mathbf{y}}$ & $\boldsymbol{E}_{\text {s }}$ \\
\hline \hline B1e, B2e, B2i & 55.8 & 4150 & 361 & 235 \\
\hline A2, B2 & 23.0 & 3550 & 235 \\
\hline b1, b2 [11] & 35.0 & 3500 & 280 & 235 \\
\hline S1a [12] & 47.7 & 3900 & 504 & 200 \\
\hline
\end{tabular}

$* f_{\text {cu- }}$ concrete cubic compressive strength; $E_{\mathrm{s}} 、 E_{f r p}$ - modules of tension rebar and FRP laminates respectively; $f_{\mathrm{y}}$-yield strength of tension rebar; $f_{f r p}$ - tension strength of FRP.
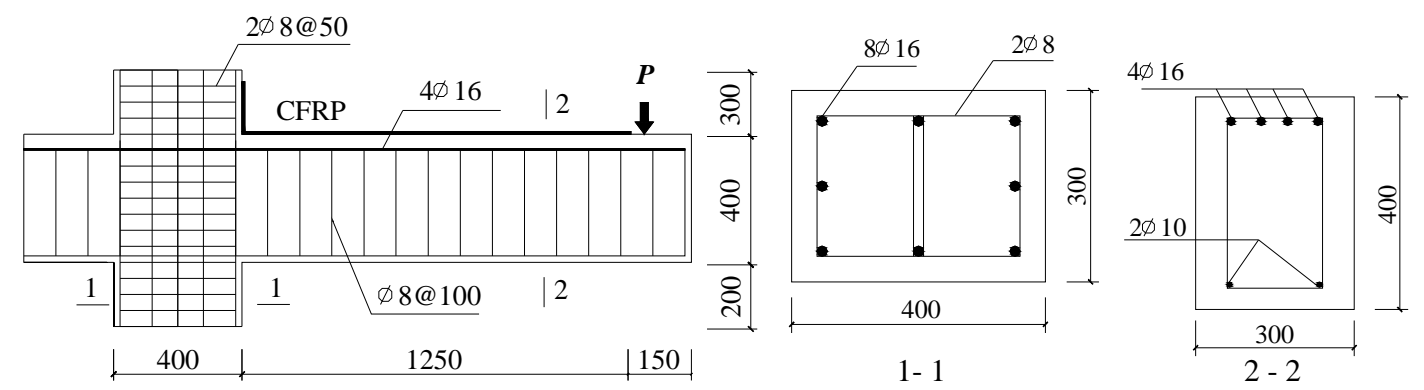

Fig. (1). Specimen details and reinforcement arrangement (for B1e, B2e, and B2i).

shown in Fig. (4), between the two halves of the CSFC, and the relative displacement became more pronounced with further load applied on the beam. When the relative displacement reached to a critical magnitude, debonding of CFRP sheets initiated at the tip of the tributary crack and propagated towards the laminates end. Fig. (5a-d) illustrates the whole debonding procedure of CFRP sheets.

Figs. (6-10) show the relationships of load-tensile strain in the CFRP laminates of series A2, B2, B1e, B2e and B2i respectively. The tensile strains in CFRP laminates of the 


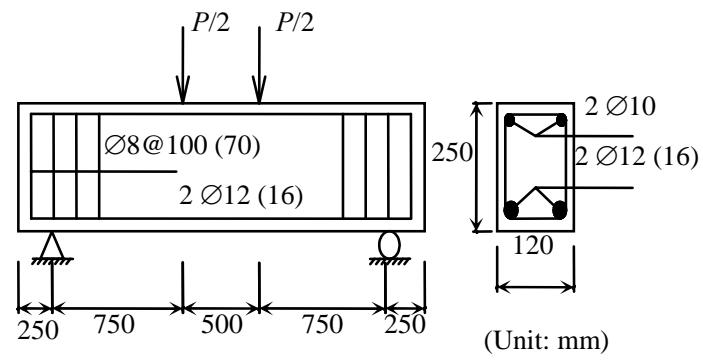

Fig. (2). Specimen details and reinforcement arrangement(for A2 and B2).
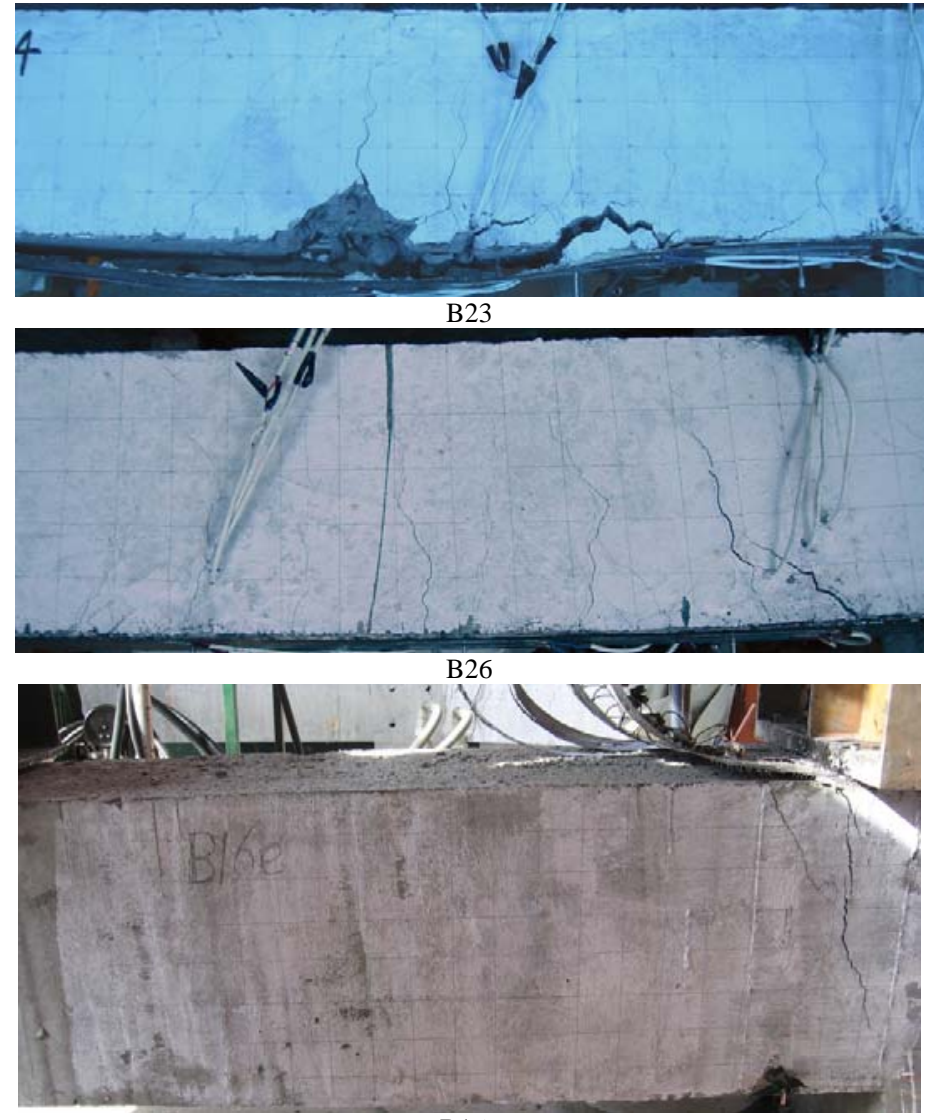

B16e

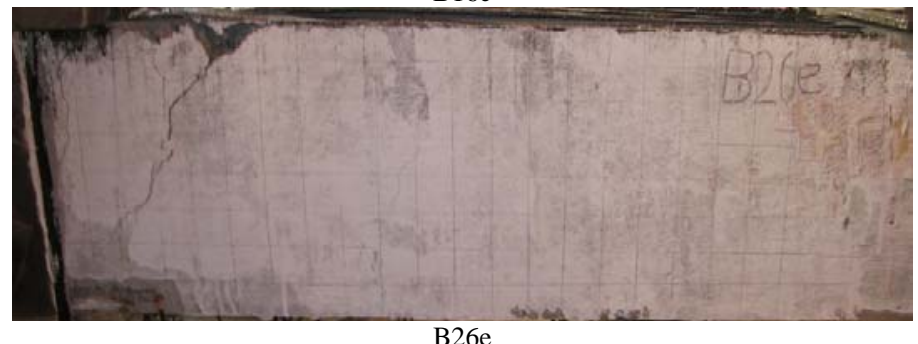

Fig. (3). Crack pattern of Beam B23, B26, B16e, and B26e.

strengthened beams at initial debonding $\varepsilon_{\mathrm{fd}, \text { tested }}$ are listed in Table 3 and Table 4, and illustrated in Fig. (11) and Fig. (12), respectively.

\section{PREVALENT MODELS PRESENTED IN CODES AND LITERATURES}

To prevent intermediate crack-induced debonding failure in flexurally FRP-strengthened RC members, most codes and proposed models define the approach that tensile strain in FRP sheets should be limited to a threshold value at which debonding of FRP sheets may occur. The prevalent Code provisions and proposed models for determining the allowable tensile strain in FRP sheets, $\varepsilon_{f \mathrm{~d}}$, are summarized in Table 5.

ACI 440.2R-08 [1] describes a modification of the debonding strain equation proposed by Teng et al.[7, 10] that 


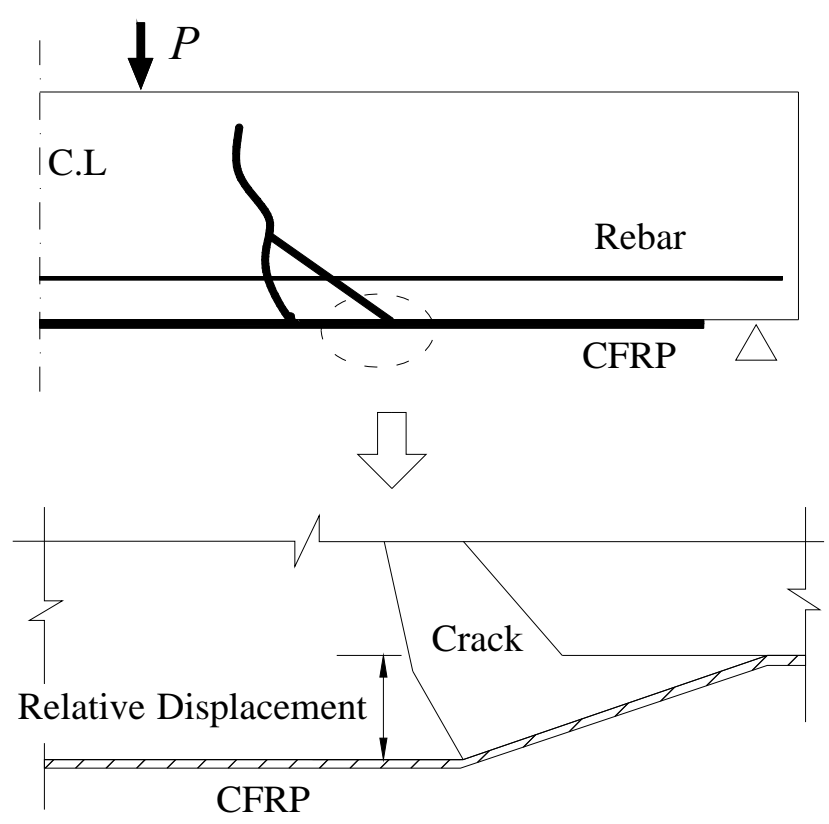

Fig. (4). Close-up view at the tip of tributary crack.

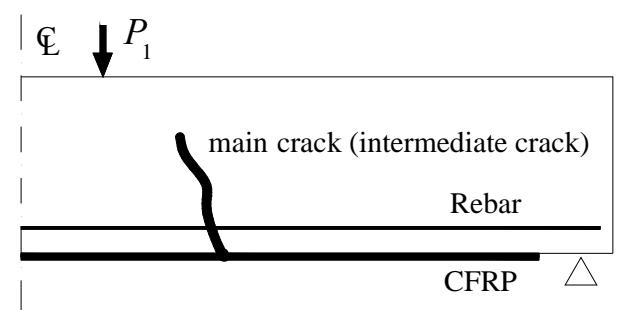

(a) formation of main crack (intermediate crack)

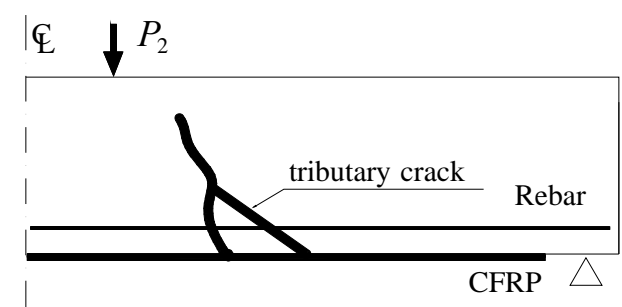

(b) formation of tributary crack

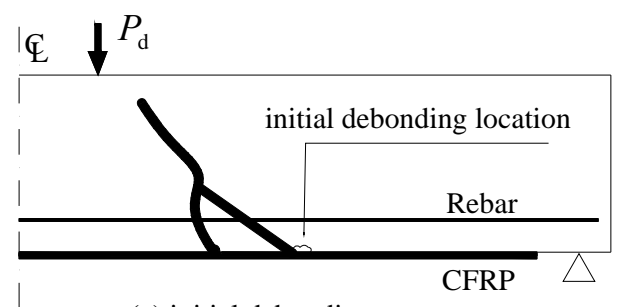

(c) initial debonding

Fig. (5). Debonding process of CFRP laminates.

was based on the investigation of a significant database of flexural member tests exhibiting FRP sheets debonding failure. The proposed equation was calibrated using average values of FRP tensile strains measured at debonding and the database for flexural tests experiencing intermediate

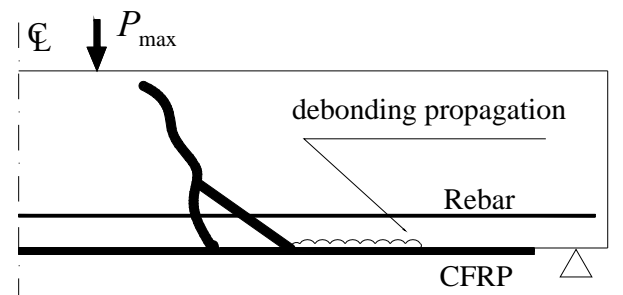

(d) debonding propagation

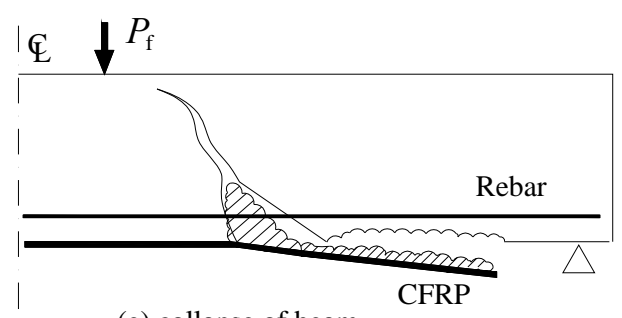

(e) collapse of beam

crack-induced debonding was used to determine the best fit coefficient of 0.41 .

JSCE recommendations [5] suggested that debonding of FRP sheets does not take place when the stress in FRP sheets at the location of flexural crack caused by the maximum 


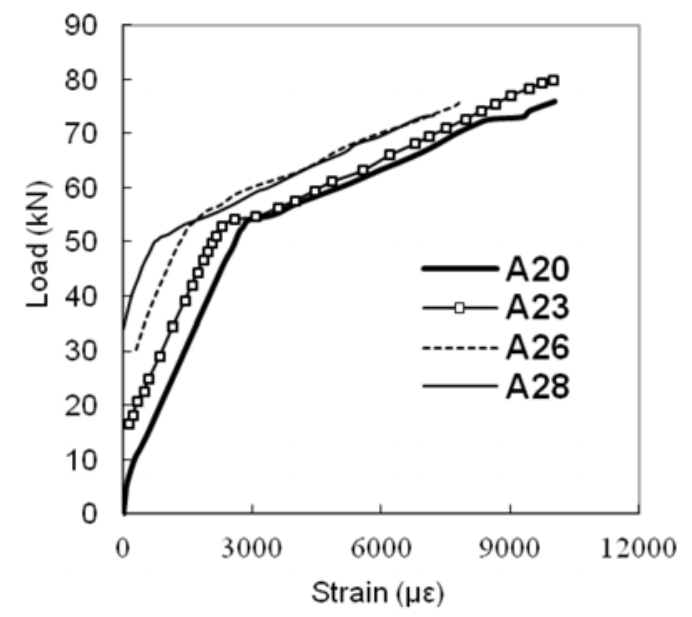

Fig. (6). Load6-FRP strain relationship of series A2.

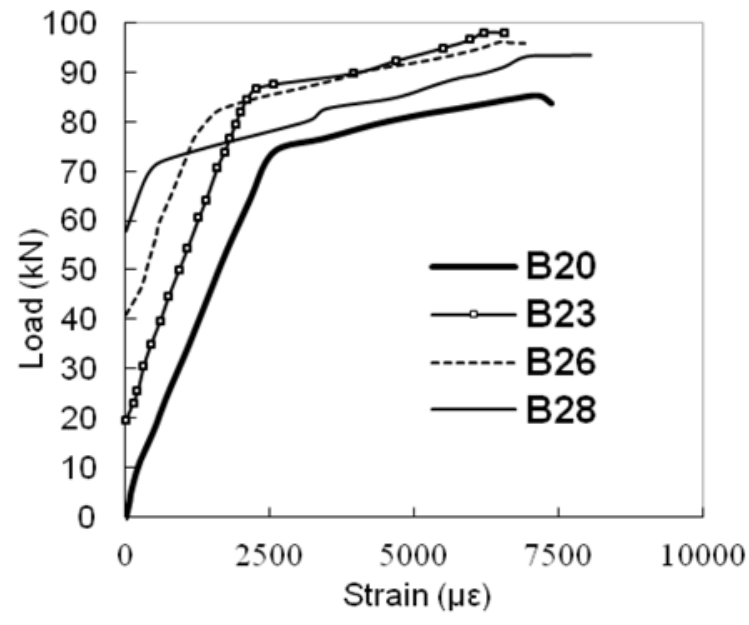

Fig. (7). Loa-FRP strain relationship of series B2.

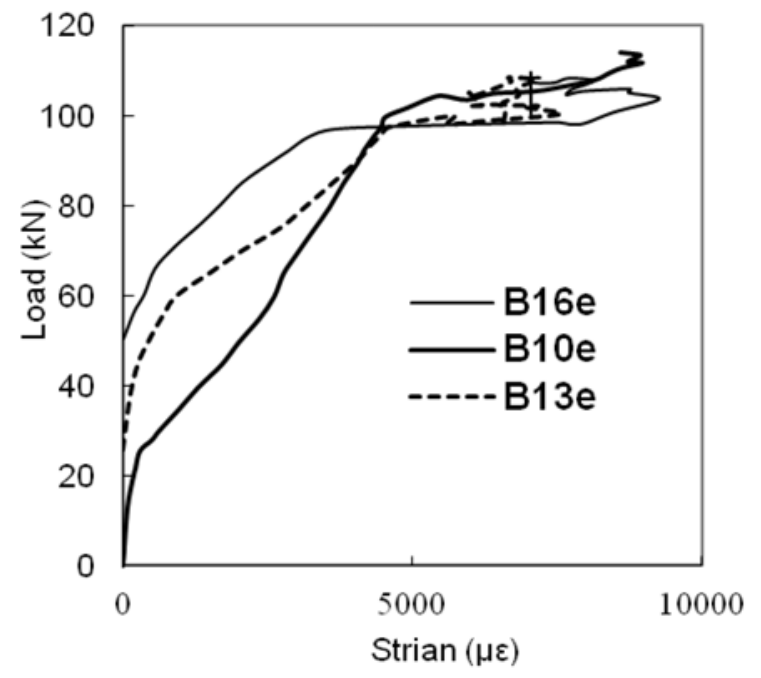

Fig. (8). Load-FRP strain relationship of series B1e.

bending moment in the member satisfies $\sigma_{f} \leq \sqrt{2 G_{f} E_{f} / t_{f}}$, and also suggested that the flexural capacity and axial load-carrying capacity of members failing due to debonding of FRP sheets may be calculated by the maximum value for the difference in tensile stress occurring

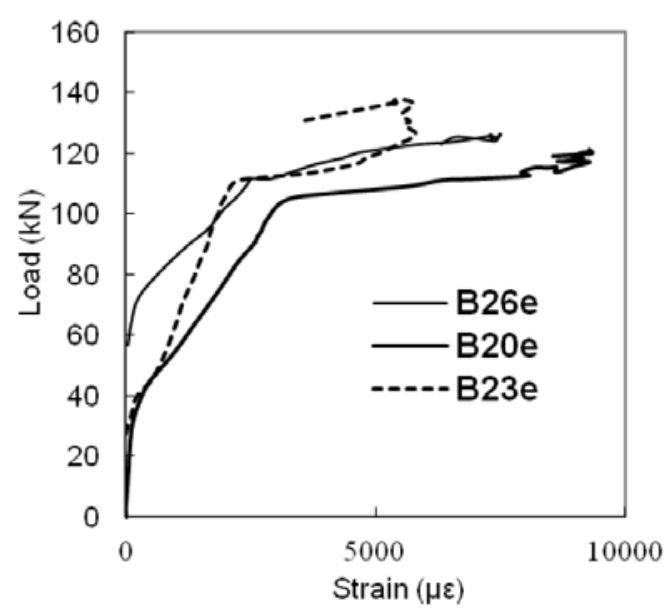

Fig. (9). Load-FRP strain relationship of series B2e.

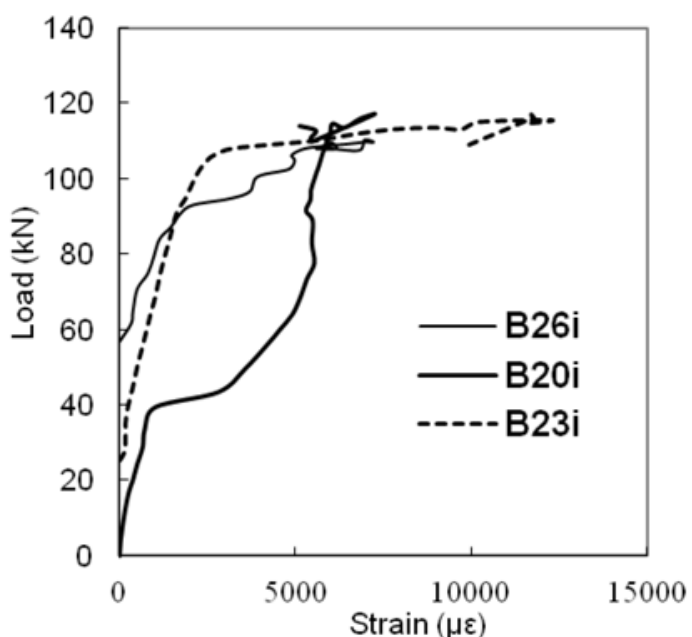

Fig. (10). Load-FRP strain relationship of series B2i.

in FRP sheets satisfy $\Delta \sigma_{f} \leq \sqrt{2 G_{f} E_{f} / t_{f}}$. However, these FRP stress equations include an interfacial fracture energy $\left(G_{\mathrm{f}}\right)$ term for FRP-concrete interface. The $G_{\mathrm{f}}$ is determined by experimental results and accounted for many factors and aspects of design. However, the $G_{\mathrm{f}}$ determined by testing and experimental results is complex and not conducive to design process.

fib bulletin-14 [2] recommends using shear stress-slip relationships to predict debonding failure in flexurally FRP-strengthened RC members. Critical bond stress and slip parameters determined from analysis of experimental data were recommended. Bulletin 14 presents three approaches to mitigate debonding failure. The first approach (fib-1) limits the maximum allowable axial load in the FRP sheets and the length required to anchor this load. To account for the effect of width of FRP sheets and RC beam $\left(b_{\mathrm{f}} / b\right)$, a $k_{\mathrm{b}}$ factor is introduced. The second approach (fib-2) presents a critical crack pattern and the bond (adhesive) stresses this pattern would cause. Bond stresses rise between flexural cracks and these stresses are then transferred to FRP laminates. The fib-2 limits the maximum stress the FRP laminates can have transferred to it, and determines an anchorage length differently than the fib- 1 . These two approaches can be used 
Table 3. Tested and Evaluated Tensile Strain in FRP Laminates at Initiation of Debonding (Code Models)

\begin{tabular}{|c|c|c|c|c|c|c|c|c|c|c|c|c|c|c|c|}
\hline \multirow{2}{*}{ Beam } & \multirow{2}{*}{$\varepsilon_{f d, t e s t}$} & \multicolumn{7}{|c|}{$\varepsilon_{f d}(\mu \varepsilon)$} & \multicolumn{7}{|c|}{$\mathcal{E}_{f d} / \mathcal{E}_{f d, t e s t}(\%)$} \\
\hline & & ACI & JSCE & fib-1 & fib-2 & CECS & TR55 & DT200 & ACI & JSCE & fib-1 & fib-2 & CECS & TR55 & DT200 \\
\hline A20 & 8971 & 7099 & 4378 & 2483 & 10555 & 10000 & 3217 & 5109 & 79 & 49 & 28 & 118 & 111 & 36 & 57 \\
\hline A23 & 8182 & 7099 & 4378 & 2483 & 10555 & 10000 & 3217 & 5109 & 87 & 54 & 30 & 129 & 122 & 39 & 62 \\
\hline A26 & 7805 & 7099 & 4378 & 2483 & 10555 & 10000 & 3217 & 5109 & 91 & 56 & 32 & 135 & 1.28 & 41 & 65 \\
\hline A28 & 6994 & 7099 & 4378 & 2483 & 10555 & 10000 & 3217 & 5109 & 102 & 63 & 36 & 151 & 1.43 & 46 & 73 \\
\hline B20 & 6253 & 7099 & 4378 & 2483 & 10555 & 10000 & 3217 & 5109 & 114 & 70 & 40 & 169 & 160 & 51 & 82 \\
\hline B23 & 5959 & 7099 & 4378 & 2483 & 10555 & 10000 & 3217 & 5109 & 119 & 73 & 42 & 177 & 168 & 54 & 86 \\
\hline B26 & 6489 & 7099 & 4378 & 2483 & 10555 & 10000 & 3217 & 5109 & 109 & 67 & 38 & 163 & 154 & 50 & 79 \\
\hline B28 & 6086 & 7099 & 4378 & 2483 & 10555 & 10000 & 3217 & 5109 & 117 & 72 & 41 & 173 & 164 & 53 & 84 \\
\hline B10e & 8386 & 15637 & 6192 & 4425 & 20913 & 10000 & 5734 & 10122 & 186 & 74 & 53 & 249 & 119 & 68 & 121 \\
\hline B13e & 7543 & 15637 & 6192 & 4425 & 20913 & 10000 & 5734 & 10122 & 207 & 82 & 59 & 277 & 133 & 76 & 134 \\
\hline B16e & 7708 & 15637 & 6192 & 4425 & 20913 & 10000 & 5734 & 10122 & 203 & 80 & 57 & 271 & 130 & 74 & 131 \\
\hline B20e & 5649 & 11057 & 4378 & 3129 & 14788 & 10000 & 4054 & 7157 & 196 & 78 & 55 & 262 & 177 & 72 & 127 \\
\hline B23e & 5636 & 11057 & 4378 & 3129 & 14788 & 10000 & 4054 & 7157 & 196 & 78 & 56 & 262 & 177 & 72 & 127 \\
\hline B26e & 6180 & 11057 & 4378 & 3129 & 14788 & 10000 & 4054 & 7157 & 179 & 71 & 51 & 239 & 162 & 66 & 116 \\
\hline B20i & 6391 & 11057 & 4378 & 3129 & 14788 & 10000 & 4054 & 7157 & 173 & 69 & 49 & 231 & 156 & 63 & 112 \\
\hline B23i & 6457 & 11057 & 4378 & 3129 & 14788 & 10000 & 4054 & 7157 & 171 & 68 & 48 & 229 & 155 & 63 & 111 \\
\hline B26i & 7216 & 11057 & 4378 & 3129 & 14788 & 10000 & 4054 & 7157 & 153 & 61 & 43 & 205 & 139 & 56 & 99 \\
\hline b1 & 2520 & 7099 & 4378 & 2483 & 10555 & 9929 & 3217 & 5109 & 282 & 174 & 99 & 419 & 394 & 128 & 203 \\
\hline b2 & 3630 & 7099 & 4378 & 2483 & 10555 & 9929 & 3217 & 5109 & 196 & 121 & 68 & 291 & 274 & 89 & 141 \\
\hline $\mathrm{S} 1 \mathrm{a}$ & 2756 & 10031 & 4249 & 2929 & 13627 & 10000 & 3795 & 6595 & 364 & 154 & 106 & 494 & 363 & 138 & 239 \\
\hline Aver. & & & & & & & & & 166 & 81 & 52 & 232 & 176 & 67 & 112 \\
\hline Cov. & & & & & & & & & 41 & 39 & 39 & 40 & 43 & 39 & 40 \\
\hline
\end{tabular}

Table 4. Tested and Evaluated Tensile Strain in FRP Laminates at Initiation of Debonding (Proposed Models)

\begin{tabular}{|c|c|c|c|c|c|c|c|c|c|c|}
\hline \multirow{2}{*}{ Reference } & \multirow[b]{2}{*}{ beam } & \multicolumn{4}{|c|}{$\varepsilon_{f d}(\mu \varepsilon)$} & \multicolumn{5}{|c|}{$\varepsilon_{f d} / \varepsilon_{f d, t e s t}(\%)$} \\
\hline & & $\boldsymbol{\varepsilon}_{f d, t e s t}$ & Teng03 & Lu & $\mathbf{W u}$ & Teng04 & Teng03 & $\mathbf{L u}$ & $\mathbf{W u}$ & Teng04 \\
\hline \multirow[t]{9}{*}{ present } & A20 & 8971 & 3073 & 5281 & 6931 & 4006 & 34 & 59 & 77 & 45 \\
\hline & A23 & 8182 & 3073 & 5281 & 6931 & 4006 & 38 & 65 & 85 & 49 \\
\hline & A26 & 7805 & 3073 & 5281 & 6931 & 4006 & 39 & 68 & 89 & 51 \\
\hline & A28 & 6994 & 3073 & 5281 & 6931 & 4006 & 44 & 76 & 99 & 57 \\
\hline & B20 & 6253 & 3073 & 5281 & 6931 & 4006 & 49 & 84 & 111 & 64 \\
\hline & B23 & 5959 & 3073 & 5281 & 6931 & 4006 & 52 & 89 & 116 & 67 \\
\hline & B26 & 6489 & 3073 & 5281 & 6931 & 4006 & 47 & 81 & 107 & 62 \\
\hline & B28 & 6086 & 3073 & 5281 & 6931 & 4006 & 50 & 87 & 114 & 66 \\
\hline & B10e & 8386 & 5435 & 11993 & 8364 & 6195 & 65 & 143 & 100 & 74 \\
\hline
\end{tabular}


Table 4 Contd....

\begin{tabular}{|c|c|c|c|c|c|c|c|c|c|c|}
\hline & B13e & 7543 & 5435 & 11993 & 8364 & 6195 & 72 & 159 & 111 & 82 \\
\hline & B16e & 7708 & 5435 & 11993 & 8364 & 6195 & 71 & 156 & 109 & 80 \\
\hline & B20e & 5649 & 3843 & 8387 & 8012 & 6195 & 68 & 148 & 142 & 110 \\
\hline & B23e & 5636 & 3843 & 8387 & 8012 & 6195 & 68 & 149 & 142 & 110 \\
\hline & B26e & 6180 & 3843 & 8387 & 8012 & 6195 & 62 & 136 & 130 & 100 \\
\hline & B20i & 6391 & 3843 & 8387 & 8012 & 6195 & 60 & 131 & 125 & 97 \\
\hline & B23i & 6457 & 3843 & 8387 & 8012 & 6195 & 60 & 130 & 124 & 96 \\
\hline Yang[11] & B26i & 7216 & 3843 & 8387 & 8012 & 6195 & 53 & 116 & 111 & 86 \\
\hline & b2 & 3630 & 3073 & 5559 & 7568 & 4520 & 85 & 153 & 208 & 125 \\
\hline Pham[12] & S1a & 2756 & 3771 & 9567 & 8243 & 7514 & 137 & 347 & 299 & 273 \\
\hline Aver. & & & & & & & 64 & 130 & 135 & 94 \\
\hline Cov. & & & & & & & 4522 & 50 & 45 & 54 \\
\hline
\end{tabular}

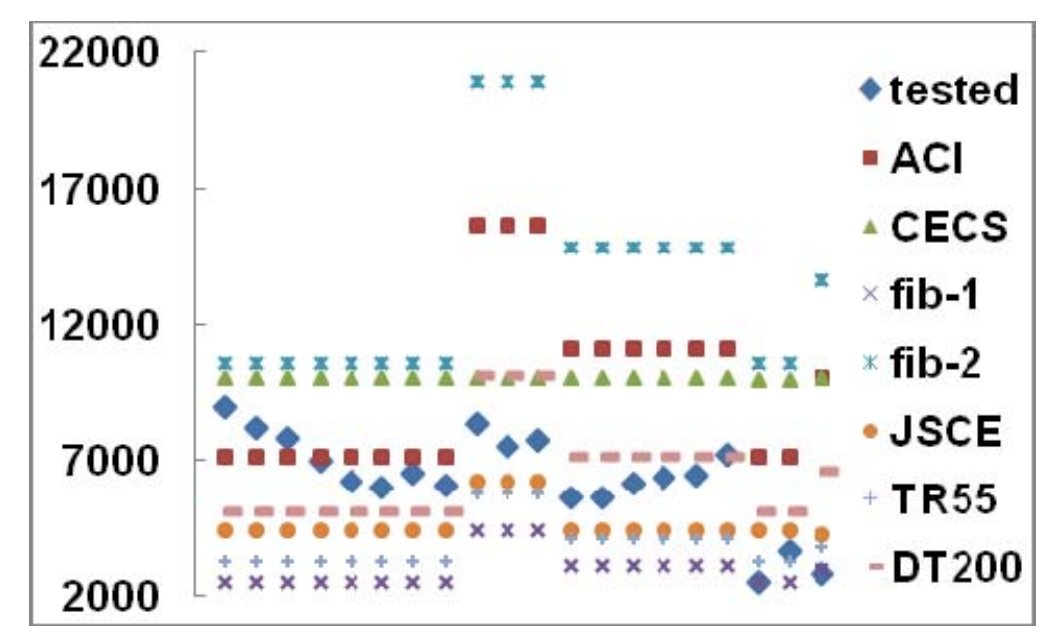

Fig. (11). Comparison of tested and predicted tensile strain in FRP laminates at initial debonding (Code models).

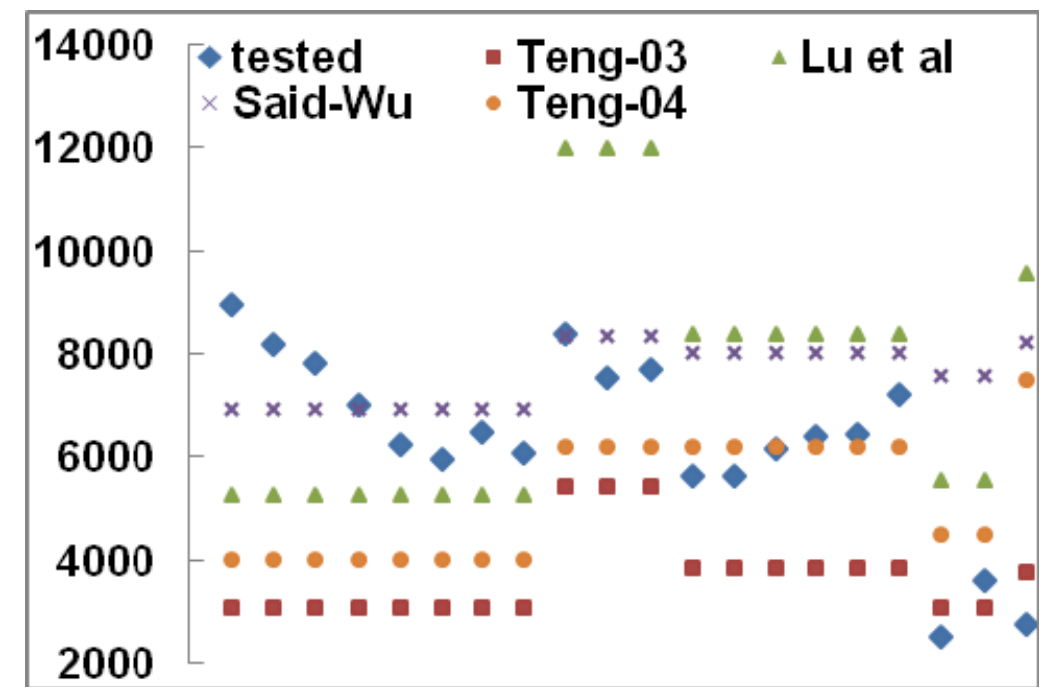

Fig. (12). Comparison of tested and predicted tensile strain in FRP laminates at initial debonding (proposed models). 
to derive allowable tensile strain equations for FRP sheets in order that debonding is prevented. The third approach is very complex and is not suitable for engineering application, and therefore, it is not assessed with the present discussion.

CECS146 [6] suggested the effective tensile strain in FRP reinforcements to prevent intermediate crack-induced debonding failure. The allowable tensile strain of FRP laminate takes the product of thickness reduction factor, $k_{\mathrm{m}}$, and the nominal ultimate tensile strain of FRP laminate, $\varepsilon_{\mathrm{cfu}}$. Furthermore, the allowable tensile strain should not be greater than $2 / 3 \varepsilon_{\text {cfu }}$ or 0.01 .

The Technical Report 55 (TR55) issued by the UK's Concrete Society [3], uses an approach similar to the fib-1 in the fib bulletin 14 to mitigate FRP laminates debonding in flexurally FRP-strengthened RC members.

To evaluate the maximum design intermediate crack-induced debonding tensile strain for FRP reinforcement, the Italian Code CNR DT200 [4] proposed a simplified method found based on a fracture mechanics approach.

Table 5. Models for Determining Allowable Tensile Strain \&fd in FRP Laminates to Mitigate Intermediate Crack-induced Debonding

\begin{tabular}{|c|c|}
\hline ACI 440 & $\varepsilon_{f d}=0.41 \sqrt{f_{c}^{\prime} / n E_{f} t_{f}} \leq 0.9 \varepsilon_{f u}$ \\
\hline JSCE & $\varepsilon_{f d} \leq \sqrt{2 G_{f} / E_{f} t_{f}}$ \\
\hline fib-1 & $\varepsilon_{f d}=\alpha c_{1} k_{c} k_{b} \sqrt{\frac{f_{c t}}{E_{f} t_{f}}}$ \\
\hline fib-2 & $\varepsilon_{f d}=c_{1} \sqrt{ } \sqrt{f_{c t} f_{c}^{\prime}} / E_{f} t_{f}$ \\
\hline CECS146 & {$\left[\varepsilon_{f d}\right]=\min \left\{\begin{array}{l}\left(1.16-\frac{n_{c f} E_{c f} t_{c f}}{308000}\right) \varepsilon_{c f u} \\
, 2 \varepsilon_{c f u} / 3,0.01\end{array}\right.$} \\
\hline TR55 & $\varepsilon_{f d}=0.5 k_{b} \sqrt{f_{c t} / E_{f} t_{f}}$ \\
\hline DT200 & 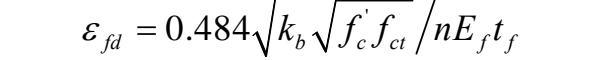 \\
\hline Teng2003 & $\left.0.48 \beta_{L} \sqrt{\left(2-\frac{b_{f}}{b}\right.}\right) /\left(1+\frac{b_{f}}{b}\right) \sqrt{\frac{\sqrt{f_{c}^{\prime}}}{E_{f} t_{f}}}$ \\
\hline Said-Wu & $\varepsilon_{f d}=0.23 f_{c}^{\prime 0.2} /\left(E_{f} t_{f}\right)^{0.35}$ \\
\hline Lu & $\varepsilon_{f d}=0.114(4.41-\alpha) \tau_{\max } / \sqrt{E_{f} t_{f}}$ \\
\hline Teng2004 & $\frac{0.54 f_{c t}}{\sqrt{E_{f} t_{f}}} \sqrt{\left(2.25-\frac{b_{f}}{b}\right) /\left(1.25+\frac{b_{f}}{b}\right)}$ \\
\hline
\end{tabular}

The Teng et al's model (Teng2003) [7] simply modified the empirical model based on analogy between debonding failure in simple shear tests and intermediate crack-induced debonding failure. Teng2003 model considered the effect of concrete compressive strength and width ratio of FRP laminates and RC beam $\left(b_{f} / b\right)$, in addition to FRP axial stiffness $\left(E_{f} t_{f}\right)$, on the debonding failure.

In light of the maximum FRP tensile strain corresponding to the ultimate experimental load of each tested beam in the database and considering the effect of concrete compressive strength, Said and Wu [9] proposed a critical value for FRP tensile strain on the debonding failure.

Using dual local debonding criterion and different bond-slip models for major flexural crack zone and rest of a beam, based on numerical simulations and regression of test data, Lu et al. [8] proposed an effective FRP tensile strain at debonding.

Teng et al. [10] presented a smeared crack approach in finite element simulation of intermediate crack-induced debonding failure. A design model for limiting FRP tensile strain, based on interfacial stress distributions determined using finite element method and verified with database of experimental tests, has been proposed.

\section{VERIFICATION OF CODE PROVISIONS AND PROPOSED MODELS}

The allowable tensile strains $\varepsilon_{\mathrm{fd}}$ for FRP laminates evaluated by these models motioned above and their statistical results of the percentage ratios of the allowable-to-experimental tensile strain in FRP laminate at debonding, are listed in Table $\mathbf{3}$ and Table $\mathbf{4}$. The validities of these models are summarized in Table $\mathbf{6}$.

The maximum, minimum, and average percentage ratios evaluated by the ACI model are $364 \%, 79 \%$, and $166 \%$, respectively, the range of predictions ratios is $285 \%$ with coefficient of variation of $41 \%$. For the fib- 1 model, its evaluated maximum, minimum, and average ratios are $106 \%$, $28 \%$, and $52 \%$ respectively, and having the range of predictions ratios of $78 \%$ with coefficient of variation of $39 \%$. However, for the fib-2 model, the maximum, minimum, and average ratios are $494 \%, 118 \%$, and $232 \%$, respectively, and having the range of predictions ratios of $376 \%$ with coefficient of variation of $40 \%$. The average allowable-to-experimental ratio assesed by the CECS model is $176 \%$ with coefficient of variation $43 \%$, and the range of the prediction ratios is $283 \%$, respectively. The TR55 shows a similar overall performance to the fib-1model, and the average, the range, and the coefficient of variation of the prediction ratios evaluated by the TR55 model are $102 \%, 39 \%$, and $66 \%$, respectively. The maximum, minimum, and average ratios by the CNR DT200 are $239 \%, 57 \%$, and $112 \%$, respectively, and having the range of predictions ratios of $182 \%$ with coefficient of variation of $40 \%$.

The maximum, minimum, and average ratios are $137 \%$, $34 \%$, and $64 \%$ evaluated by the Teng2003 model, respectively, and the range of predictions ratios is $103 \%$ with coefficient of variation of $40 \%$. The maximum, minimum, and average ratios are $273 \%, 45 \%$, and $94 \%$ asseded by the the Teng2004 model, respectively, the range of predictions 
Table 6. Summary of Validities of Different Models for Evaluating Allowable Tensile Strains in FRP Laminates at Initial Debonding, (\%)

\begin{tabular}{|c|c|c|c|c|}
\hline Models & Max. ratio & Min. ratio & Average & Cov. \\
\hline \hline ACI 440 & 364 & 79 & 166 & 176 \\
\hline CECS146 & 393 & 111 & 81 & 33 \\
\hline JSCE & 174 & 49 & 52 & 39 \\
\hline fib-1 & 106 & 28 & 232 & 40 \\
\hline fib-2 & 494 & 118 & 67 & 39 \\
\hline TR55 & 138 & 36 & 64 & 40 \\
\hline DT200 & 239 & 57 & 136 & 40 \\
\hline Teng2003 & 137 & 74 & 130 & 45 \\
\hline Said-Wu & 300 & 59 & 94 & 50 \\
\hline Lu & 347 & 45 & 54 \\
\hline Teng2004 & 273 & & & 40 \\
\hline
\end{tabular}

ratio is $228 \%$. According to the average ratio, this model seems suitable to evaluate the allowable tensile strain; however, the evaluated results of this model have the highest dispersion with coefficient of variation of $55 \%$. The maximum, minimum, and average ratios are 347\%, 59\%, and $130 \%$ calculated by the Lu model, respectively. The range of predictions ratios is $289 \%$ with coefficient of variation of $50 \%$. The average allowable-to-experimental ratio is $136 \%$ by the $\mathrm{Wu}$ model, and the range of prediction ratios is $223 \%$ with coefficient of variation $45 \%$.

The statistical results show that all the predicted allowable tensile strains depict a great difference with the experimental results and have a high level of dispersion. Similar predictions of the maximum allowable strain to mitigate intermediate crack-induced debonding, were found in these models and provisions issued by ACI 440.2R-08, fib-2, DT200, and CECS146; and proposed by Said-Wu, Lu et al, and Teng2004. In all these cases, these proposed models provided non-conservative estimations of FRP tensile strain to cause debonding. These models highly overestimate the debonding tensile strains for FRP laminates. The JSCE, TR-55, fib- 1 and Teng2003 provide very conservative estimations of allowable tensile strains for FRP laminates debonding.

\section{CONCLUSIONS}

Based on the results obtained from the current study, the following conclusions may be drawn:

1) All the allowable tensile strains of FRP laminates for preventing debonding failure evaluated by these proposed models exhibit a great difference with experimental results and have a high level of dispersion. Therefore, these models are not suitable to evaluate the allowable tensile strain in FRP laminates to mitigate debonding failure in FRP-strengthened RC beams.

2) Most of the models are basically developed by simply shear test results. As it is well known, the simply shear test cannot reflect all the factors affecting the debonding failure of FRP laminates in flexural FRP-strengthened RC members. This is why the predicted results are rather very conservative or very non-conservative, and have a high level of dispersion.

3) Intermediate crack-induced debonding failure is the dominant failure mode in flexurally FRP-strengthened RC members, more research should be done on this failure pattern to make better understanding of its mechanism and to ensure its safety of the strengthened members.

\section{CONFLICT OF INTEREST}

The authors confirm that this article content has no conflicts of interest.

\section{ACKNOWLEDGEMENTS}

None declared.

\section{REFERENCES}

[1] ACI-440.2R, "Guide for the Design and Construction of Externally Bonded FRP Systems for Strengthening Concrete Structures," ACI, Farmington Hills. Mich.2008.

[2] fib, "Externally bonded FRP reinforcement for RC structures, Bulletin 14," Lausanne, Switzerland: Fe'de'ration Internationale du Be'ton, 2001, pp. 51-58.

[3] Concrete Society, "Design Guidance on Strengthening Concrete Structures using Fiber Composite Materials", "Technical Report 55" Concrete Society Camberley, Surrey, UK,2004.

[4] CNR DT200, "Guidelines for design, execution and control of strengthening interventions by means of fibre-reinforced composites - materials, reinforced concrete and prestressed concrete structures, masonry structures," Rome, Italy: National Research Council, Advisory Committee on Technical Regulations for Constructions, 2004, p. 164.

[5] JSCE, "Recommendations for updating of concrete structures with use of continuous fiber sheets, "Concrete Engineering Series 41, Japan Society of Civil Engineers, pp. 31-34, 2001.

[6] CECS146, Techinical specification for strengthening concrete structures with carbon fiber reinforced polymer laminate, China Planning Press, Beijing 2003, p. 53. 
[7] J. G. Teng, S. T. Smith, J. Yao, and J. F. Chen, "Intermediate crack-induced debonding in RC beams and slabs," Constr. Build. Mater., vol. 17, pp. 447-462, 2003.

[8] X. Z. Lu, J. G. Teng, L. P. Ye, and J. J. Jiang, "Intermediate Crack Debonding in FRP-Strengthened RC Beams: FE Analysis and Strength Model," J. Composites Constr., vol. 11, pp. 161-174, 2007.

[9] H. Said and Z. Wu, "Evaluating and proposing models of predicting IC debonding failure," J. Composites Constr., vol. 12, pp. 284-299, 2008.

[10] J.G. Teng, X.Z. Lu, L.P. Ye, and J.J.Jiang, "Intermediate Crack Debonding in FRP-Strengthened RC Beams: FE Analysis and
Strength Model," In: Proceedings of the 4th International Conference on Advanced Composite Materials for Bridges and Structures, Calgary, Alberta: Canada, 2004, pp. 1-12.

[11] L. P. Ye, T. Q. Fang, Y. X. Yang, and Q. R. Yue, "Experimental Researh of Flexural Debonding Performances About RC Beams Strengthened with CFRP Sheets," Build. Struct., vol. 33, pp. 61-65, 2003.

[12] H. B. Pham and R. Al-Mahaidi, "Experimental investigation into flexural retrofitting of reinforced concrete bridge beams using FRP composites," Compos. Struct., vol. 66, pp. 617-625, 2004.

(C) Li et al.; Licensee Bentham Open.

This is an open access article licensed under the terms of the Creative Commons Attribution Non-Commercial License (http://creativecommons.org/licenses/ by-nc/3.0/) which permits unrestricted, non-commercial use, distribution and reproduction in any medium, provided the work is properly cited. 